\title{
Tissue Engineering Strategies in Ligament Regeneration
}

\author{
Caglar Yilgor, ${ }^{1}$ Pinar Yilgor Huri, ${ }^{2}$ and Gazi Huri ${ }^{3}$ \\ ${ }^{1}$ Department of Orthopedics and Traumatology, Hacettepe University Faculty of Medicine, Sihhiye, 06100 Ankara, Turkey \\ ${ }^{2}$ Department of Biochemistry, Cukurova University Faculty of Medicine, Balcali, 01330 Adana, Turkey \\ ${ }^{3}$ Department of Orthopedics and Traumatology, Cukurova University Faculty of Medicine, Balcali, 01330 Adana, Turkey
}

Correspondence should be addressed to Caglar Yilgor, caglaryilgor@gmail.com

Received 15 October 2011; Revised 9 November 2011; Accepted 14 November 2011

Academic Editor: Wasim S. Khan

Copyright () 2012 Caglar Yilgor et al. This is an open access article distributed under the Creative Commons Attribution License, which permits unrestricted use, distribution, and reproduction in any medium, provided the original work is properly cited.

Ligaments are dense fibrous connective tissues that connect bones to other bones and their injuries are frequently encountered in the clinic. The current clinical approaches in ligament repair and regeneration are limited to autografts, as the gold standard, and allografts. Both of these techniques have their own drawbacks that limit the success in clinical setting; therefore, new strategies are being developed in order to be able to solve the current problems of ligament grafting. Tissue engineering is a novel promising technique that aims to solve these problems, by producing viable artificial ligament substitutes in the laboratory conditions with the potential of transplantation to the patients with a high success rate. Direct cell and/or growth factor injection to the defect site is another current approach aiming to enhance the repair process of the native tissue. This review summarizes the current approaches in ligament tissue engineering strategies including the use of scaffolds, their modification techniques, as well as the use of bioreactors to achieve enhanced regeneration rates, while also discussing the advances in growth factor and cell therapy applications towards obtaining enhanced ligament regeneration.

\section{Introduction}

Fibrous connective tissue bands connecting two or more bones are called ligaments. Ligaments augment joint stability and resist to forces to prevent excessive motion. Extracellular matrix (ECM) forms $80 \%$ of the tissue volume and fibroblasts make up the remaining $20 \%$. The dry weight of a ligament consists of collagen (75\%), elastin (1\%), proteoglycans, and glycoproteins [1]. $90 \%$ of the collagen is type I and $10 \%$ is type III.

Although ligaments sustain excessive mechanical loads, they have a poor regeneration capacity with their low cell density and low nutrient and oxygen requirements. Thus, ligaments are repaired by a weaker and disorganized tissue which is prone to reinjury [2]. Using autografts for ligament reconstruction remains the gold standard with their high mechanical strength and compatibility, besides having high revascularization and remodeling capacities [3]. However, donor site morbidity and damage, thus, pain, and altered harvest site biomechanics that sometimes require a second invasive procedure are the drawbacks of autografts [4-6]. Allografts, on the other hand, exclude the risks associated with autografts, such as donor site morbidity; however, they carry additional risks of disease transmission, infection, and allergic reactions in addition to their lower early cellularity and less revascularization [7]. These circumstances drive attention to other techniques for ligament reconstruction, such as the use of biomaterials, cell therapies, and tissue engineering strategies, to promote a more functional healing. Preserving the native insertions and proprioceptive functions of the ligaments are advantages of these techniques leading to functional healing, over the surgical reconstruction of the tissue.

Tissue engineering strategy involves the use of biodegradable and biocompatible biomaterials with adequate structural and mechanical properties to mimic the organization of the native tissue, along with cells isolated from the healthy proportion of the patients own ligament, or other alternative cell sources such as stem cells, and growth factors to regulate the function of these cells. Conceptually, tissue engineering aims to improve the quality of the processes associated with the healing of the ligaments by creating viable artificial substitutes in the laboratory and their transplantation to the patient after in vitro maturation. Therefore, tissue engineering holds promise for the future in terms of decreasing the need for ligament grafting procedures while reducing 
the risks associated with them, such as rejection and tissue mismatch, as the construct would carry the patient's own cells.

From the clinical point of view, the main advantages offered by the use of tissue engineered ligament could listed to be minimal patient morbidity, simpler surgical technique, reliable fixation methods, rapid return to preinjury functions, minimal risk for infection or disease transmission, biodegradation at a rate that provides adequate mechanical stability, and supporting host tissue ingrowth [8]. Cellular adherence and matrix formation are also included in the design factors of ligament tissue engineering [9].

Another important aspect that should be taken into account in the clinical translation of tissue engineered ligament is the ligament-bone interface, which consists of a multilayered transition zone. The tissues involved in this interface display distinct mechanical properties; the ligament is strong in tension and bone is strong in compression [10, 11]. Therefore, interface is challenging for tissue engineers to mimic creating one of the current field of interests in ligament tissue engineering.

Anterior cruciate ligament (ACL) and medial collateral ligament (MCL) as well as the glenohumeral ligaments are the most frequently practiced ligament tissues to date, while all ligaments are in the pursuit of tissue engineering and studies are being carried out to create functional biological replacements of these tissues.

\section{Growth Factor and Cell Therapies in Ligament Repair}

Growth factors are regulators of cellular activities and several of them, including insulin like growth factor I (IGF-I), transforming growth factor- $\beta$ (TGF- $\beta$ ), vascular endothelial growth factor (VEGF), basic fibroblast growth factor (bFGF), epidermal growth factor (EGF), and platelet derived growth factor (PDGF), were shown to be effective in the healing of ligament repair. In vitro and in vivo studies have shown that these growth factors have the capability to improve ligament cell proliferation and matrix formation alone or in combination [12-21]. Deie et al. have demonstrated that rabbit MCL fibroblasts are responsive to TGF- $\beta 1$ and EGF [12] and Hildebrand et al. suggested that use of PDGF may improve the quality of ligament healing [13]. In a similar study, TGF$\beta 1$ and IGF were shown to modify the metabolic activity of cells of healing ligaments in rabbit MCL [14]. Marui et al. have reported that topical application of TGF- $\beta 1$, alone or in combination with EGF, may strengthen the ligament by increasing matrix synthesis during its healing processes [15]. Age and fibroblast origin were also found to be important factors in determining the proliferative response to PDGF and bFBF $[12,16]$. Schmidt et al. also reported that PDGF, bFGF, and IGF-I can stimulate cell proliferation in ligaments [18]. Kobayashi et al. demonstrated that the application of bFGF enhances neovascularization and the formation of granulation tissue in lacerated canine ACL [22]. Kobayashi et al., in a rabbit study, have developed a quantitative method to assess cell migration and their findings supported previous qualitative observations [23]. They used a mathematical method to analyze cell densities in a wound model and showed that cells moved into cell-free areas [23]. DesRosiers et al. have combined EGF, PDGF, TGF- $\beta 1$, and IGF-I two by two and analyzed their effects on cell proliferation and proteoglycan synthesis. Their results showed that EGF and PDGF had a greater effect than TGF- $\beta 1$ and IGF-I on cell proliferation and proteoglycan production was increased by all four factors, with TGF- $\beta 1$ having the strongest effect [19]. Others have demonstrated that combination of growth factors can have synergistic effects [20, 21]. Letson and Dahners demonstrated that ligaments treated with a combination of PDGF plus IGF-I and PDGF plus bFGF had increased rupture force, stiffness, and breaking energy [20]. A similar study showed that synergistic effect of combination of bFGF, TGF- $\beta 1$, bovine insulin, and PDGF was as much as 20 -fold of the effects of individual factors [21].

Platelet rich plasma (PRP) and collagen-PRP-complex (CPC) were also shown to be effective in the improvement of ligament healing. In a study of Liu et al., platelet concentration was shown to have a dose-response relationship with proliferation of mesenchymal stem cells (MSCs), fibroblasts, and production of collagen type I in vitro [24]. Thus, PRP is attributed to be an effective agent for ligament healing $[25,26]$. Studies have supported this idea, showing effects of PRP on intraarticular ligament homogeneity [27], increase in load at yield, maximum load, and linear stiffness [28]. However, other studies concluded that application of PRP did not yield any advantage over standard ACL reconstruction procedures $[29,30]$. In contrast, the use of CPC on ACL allografts was reported to inversely correlate with sagittal plane laxity [31]. Murray et al. used CPC to fill the ACL wound site at the time of suture repair in pigs and concluded that CPC scaffolds result in improved biomechanical properties [28].

Cell sources used in the repair of ligaments include MSCs which have revealed great potential in tissue engineering as a cell source that can differentiate into various connective tissue cell types including fibroblasts [32-35]. It was shown that MSC concentration at the site of injury can be augmented by allogenic MSCs delivered via the bloodstream [33]. Dermal fibroblasts are another possible cell source [36] which is easier to harvest and also display low donor site morbidity. Presence of such cells was reported to enhance peak breaking stress of hybrid collagen biomaterials in an in vitro study [37].

Functioning of certain cells can be altered via introducing DNA fragments using retroviral, adenoviral or liposomal carriers [38]. After successfully introducing a marker gene and detecting its expression in rabbit MCL and ACL [39], potential therapeutic genes such as TGF- $\beta 1$, IGF-1, PDGF, and bone morphogenetic protein- (BMP-) 12 were also successfully introduced and expressed [40-43]. Steinert et al. have investigated the transfer of IGF-I genes using an adenovirus vector to a collagen hydrogel inserted between the cut ends of the ACL and reported promising results [40]. PDGF gene introduction was shown to enhance and accelerate matrix synthesis in a rat study and therefore claimed to be a useful tool for improving ligament repair [41]. Collagen hydrogels were used to augment ACL healing in a bovine 
model and increased cell accumulation was reported with TGF- $\beta 1$-transferred hydrogels [42]. BMP-12 gene transfer was reported to result in a twofold increase of tensile strength and stiffness of repaired tendons in a chicken model [43].

\section{Scaffolds in Ligament Reconstruction}

Scaffolds are important components of tissue engineering strategy as they define the ultimate shape of the construct while providing the required mechanical strength during regeneration and proper cell attachment sites. Although there are alternate views on the ideal material, and the structure and composition of it, for ligament tissue engineering, it is generally believed that a scaffold that allows immediate load bearing and degrades at a comparable rate with the tissue regeneration would form the ideal engineered ligament [9].

Natural and synthetic materials have widely been used as ligament replacements in the forms of gels, membranes, or 3D scaffolds. Collagen, silk, hyaluronic acid (HA), ECM bioscaffolds such as porcine small intestine submucosa (SIS), and urinary bladder membrane (UBM) and polyhydoxyalkanoates (PHAs) such as poly( $\beta$-hydroxybutyrate) (PHB), poly-3-hydroxybutyrate-co-hydrovalerate (PHBV), and poly-3hydroxy-10-undecenoate (PHUE-O3) are examples of potential natural replacements, whereas Dacron polyester, poly(glycolic acid) (PGA), poly(L-lactic acid) (PLLA), pol$y$ (lactic acid-co-glycolide) (PLGA), high molecular weight PLGA (HMW PLGA), poly( $\varepsilon$-caprolactone) (PCL), pol$\mathrm{y}$ (ethylene oxide) (PEO), and poly(urethane urea) (PUUR) are examples of synthetic materials.

Collagen was one of the first natural scaffold materials to be used in ligament reconstruction as it is the natural component of the native tissue and has great ability to support ligament fibroblast growth under static tension [44]. However, collagen scaffold alone was found to be ineffective to enhance suture repair of the ACL [45]. Fibroblast-seeded collagen scaffolds, on the other hand, were more effective in ligament regeneration $[44,46-48]$. It was shown in vitro that such scaffolds are consolidated with ECM and that DNA content increased rapidly over the first weeks [46]. In vivo studies have shown that fibroblast-seeded ligament analogs remain viable after implantation into the knee joint $[47,48]$. Collagen scaffolds were also combined with PRP $[25,28]$ and various autologous and allogenic cell types $[49,50]$ to achieve enhanced mechanical properties and repair.

Silk was also effectively used as a ligament replacement material. It has a relatively slow rate of degradation within the body compared to collagen and other most widely used natural biomaterials which could possess an advantage in load-bearing applications. Its main advantage is its remarkable tensile strength and toughness compared to most natural materials although being lower than native human ACL [51]. The use of pure silk was shown to include problems associated with the sericin protein it contains as it may lead to allergic reactions [52]. This issue was tried to be overcome by the use of virgin silk, in which this allergen was extracted $[53,54]$.

Silk fibroin is a protein excreted by silkworms and isolated from sericin [55]. This protein has surface amino acids for cell adhesion and slowly degrades in aqueous solutions [56]. It can be fabricated into gels, films, and fibers. In animal models, silk fibroin has been reported to regenerate ligaments, thus claimed to be an excellent natural biomaterial alternative to collagen [9]. MSC-seeded silk fibroin scaffolds [57] and hybrid silk fibroin-silk sponge scaffolds [58] were also developed and demonstrated to be good alternatives for in vivo ligament replacement.

Composite natural scaffolds have also been fabricated using silk and collagen and then seeded with cells [59]. Due to its rapid tissue ingrowth, this chimeric silk-collagen sponge matrix was suggested to be an effective treatment for MCL transactions [59].

ECM bioscaffolds such as SIS and UBM are composed of collagen and contain cytokines and growth factors [60, 61]. ECM bioscaffolds were found to support ligament regeneration and repair and claimed to be effective candidate tools for ligament tissue engineering [62-67]. Dejardin et al. used SIS to promote regeneration of large fascial defects in adult dogs and reported promising results [62]. In a goat model, Badylak et al. reported that SIS holds promise as a resorbable bioscaffold for ACL repair [63]. MCL was shown to have better mechanical properties when SIS is applied in the healing process $[64,65]$. Musahl et al. reported that SIS treatment improves not only the mechanical properties but also the histological appearance of the MCL [66]. In a more recent study, Woo et al. demonstrated that SIS enhances the fibril morphology and the collagen composition of healing MCL in rabbits [67].

In a rabbit study, Wiig et al. bilaterally lacerated ACL in the midsubstance and injected hyaluronic acid in one and saline to the other knee. The results showed increased synthesis of type III collagen in the hyaluronic acid treated injured ACL [68]. Recently, it was reported that chitosan-hyaluronan hybrid fibrous scaffolds enhance type I collagen production and improve mechanical strength in the engineered ligament in vivo [69]. PHB, PHBV, and PHUE-O3 were also reported to be good candidates for ligament tissue engineering [70].

The use of synthetic polymeric biomaterials has several advantages over the natural ones, such as they are more readily available, can be produced in large scale with low cost, and are easier to process. Moreover, their mechanical strength is mostly higher compared to natural biomaterials which offer an advantage in the engineering of tissues which are required to handle mechanical forces such as ligaments. On the other hand, they may have some disadvantages such as involving unnatural degradation byproducts and may lack functional chemical cellular binding groups [9].

Among the synthetic polymeric biomaterials used in ligament regeneration, Dacron, which is basically poly(ethylene terephthalate) (PET), is a nondegradable ligament prosthesis. It was shown that seeding of fibroblasts allowed for a more uniform connective tissue encapsulation [71].

Polyhydroxyesters that degrade by hydrolysis such as PLLA and PGA are biodegradable polymers that are popularly used in ligament repair $[72,73]$. Braided PLGA scaffolds were claimed to have great promise for ligament engineering [74] while PLLA scaffolds were shown to be a more appropriate choice for ligament tissue engineering because of their 
slower degradation rate [75]. HMW PLGA was reported to allow more MSC attachment and proliferation than PLGA [76]. To optimize degradation rates and hydrophilicity that determines cell adhesion, composites of these materials are often fabricated [77].

A newer synthetic polymer, PUUR, was shown to have a similar loading profile as a postmortem-tested human ACL [78], and no relaxation or fatigue was observed after 50 repetitive cyclic loading [79]. PUUR was reported to keep at least $50 \%$ of its original tensile strength at body temperature for more than 9 months. Taking into account together with the strength and stiffness properties, PUUR was claimed to fulfill the desired properties for ACL reconstruction [80]. It was also shown that native cells have migrated into the implanted PUUR and that neovascularization between its fibers was detected, indicating that it is well tolerated by the host [79]. In a rabbit study where PUUR was used as a full ACL prosthesis, the knee function was reported to be intact even after 24 months [79].

\section{Engineering the Ligament-Bone Interface}

The ligament-bone interface consists of four distinct but continuous regions: ligament, noncalcified fibrocartilage, calcified fibrocartilage, and bone [81-83]. It is well known that the native interface is not regenerated in case of an injury $[84,85]$. For recreating this multi-zone organization, it is essential to have a stratified or multi-phased scaffold that exhibits a continuing increase in mechanical properties through the scaffold phases [86]. In addition to such stratified, multiphased or 3D braided scaffolds, stem cell applications, cytokines, BMP-2, and BMP-12 are also considered in order to improve regeneration of this interface.

Coating of tendons with calcium phosphate layer [87], TGF- $\beta$ [88], and BMP-2 [89-91] was found to improve osteointegration between ACL and bone tunnel, however not the fibrocartilage interface.

Multiphased, porous knitted silk [92], 3D braided PLLA [93], and poly(ethylene glycol) hydrogel incorporating HA scaffolds [94] were engineered to mimic ligament-bone interface and promising results were reported. Another innovative triphasic scaffold that has three distinct yet continuous phases including chondrocytes along with fibroblasts and osteoblasts was developed intending to regenerate the fibrocartilagineous interface $[95,96]$. A further engineered ligament equivalent is reported to be a fibroblast-embedded fibrin gel with cast brushite anchors [97]. A multiphase tissue-engineered construct for ACL grafts using bone marrow origin MSCs was presented as a viable option for ACL replacement [98] using sheep as a model system.

\section{Physical and Chemical Modification of Ligament Tissue Engineering Scaffolds}

It is important to optimize cell-biomaterial interactions to achieve enhanced regeneration, mainly in terms of cell attachment and ability of cell proliferation and matrix secretion. Cell surface integrin receptors typically mediate cellmatrix interactions and the most common peptide sequence is arginine-glycine-aspartic acid (RGD) which has been used in a number of studies to achieve enhanced cell attachment [99].

In general, phosphate, amide, and sulfonate groups are used as functionalizing groups in tissue engineering applications [9]. To enhance scaffold-mediated tissue repair, growth factors are also used for signaling [100]. In a porcine model, it was shown that adding CPC to a suture repair enhances biomechanical and histological properties of the ACL via increasing cellularity within the healing ligament [26]. Silk fibroin was functionalized with MSC seeding and blending it with hyaluronan [101]. Functionalization of PET scaffolds was done with poly(sodium styrene sulfonate) (PNaSS) which was reported to have more fibroblastic adherence than nonfunctionalized fibers [102].

\section{Bioreactors in Ligament Tissue Engineering}

The body itself can be used as a "bioreactor" when cell-scaffold composites are directly implanted into the injured site or ex vivo bioreactors can be used for a period of time to achieve mature constructs prior to transplantation [103]. Ex vivo bioreactors allow application of controlled biochemical and physical regulatory signals to guide differentiation, proliferation, and tissue development [103].

Initial bioreactors applied uniaxial forces to tethered constructs [104]. More recent bioreactors are capable of applying multiaxial and cyclic strains, which better mimics the native physiology [8, 105-107]. Although the use of such bioreactor systems is a relatively new practice in ligament tissue engineering, the results are promising, which positively affects the cell proliferation and differentiation of stem cells towards musculoskeletal lineages in most if not all cases [9]. However, type, magnitude, and duration of mechanical stimuli and, thus, the ideal stimulation regime have not yet been described [9].

Application of mechanical loading was reported to have positive effects on cellular proliferation in various studies [104, 108, 109]. Mechanical loading was also shown to effect cellular morphology and alignment [104, 108-111]. The differentiation of MSCs in the presence of mechanical loads was shown to tend towards the ligament lineage [108, 112115]. ECM synthesis and remodeling [109, 116-120] is another factor that is shown to be affected by mechanical loading. Studies have also reported that enzyme activity and growth factor expression [109, 121-123] and (6) Collagen type I, collagen type III, elastin, and tenascin-C expression in MSCs [108, 112-114] were increased with the application of mechanical loads.

\section{Conclusion and Future Directions}

This manuscript provides an overview of the previous applications and current concepts in ligament tissue engineering. Combining different approaches seems to be mandatory in order to assemble ligament-like tissue structures. Such combinations may include braiding, stratifying, knitting, or 3D braiding scaffolds as well as merging scaffolds with sponges, merging different material types in a single multiphased 
scaffold, aligning or cross-linking its cellular content, functionalizing its surface, and adding mechanical ex vivo stimulation. Scaffolds further need to possess a porous structure and full pore interconnectivity to allow ingrowth of native cells and connective collagen fibers.

Biomimicry is the main strategy with the intention of developing functional artificial tissues in tissue engineering. To mimic the structure as well as function of the native tissue, the interface is a great challenge and multiphased scaffolds constitute a promising option to fulfill this need.

Various types of growth factors, stem cells, cytokines and plasma ingredients; gene delivery; a range of natural and synthetic materials, and effects of mechanical loading and functionalizing have been and are being investigated. Clearly, much work remains but there are exciting and promising advances. Important future targets should include developing scaffolds that match tissue ingrowth rate with its degradation rate, matching native biomechanical properties, and should have improved strength and biological integrity as well as being able to mimic the properties of tissue interfaces.

Although many steps have been taken, to date, tissue engineering is probably still far from producing the ideal bioscaffold to replace, repair, or regenerate injured ligaments. Clinician-scientist coordination is indispensable for achieving such a goal. Along with this multidisciplinary approach, interdisciplinary contribution from biologists, chemists, biomaterial scientists, and tissue engineers is needed for meeting patients' demands.

\section{References}

[1] C. Carlstedt and M. Nordin, "Biomechanics of tendons and ligaments," in Basic Biomechanics of the Musculoskeletal System, M. Nordin and V. H. Frankel, Eds., pp. 59-74, Lea \& Febiger, Malvern, Pa, USA, 1989.

[2] T. Molloy, Y. Wang, and G. A. C. Murrell, "The roles of growth factors in tendon and ligament healing," Sports Medicine, vol. 33, no. 5, pp. 381-394, 2003.

[3] R. P.A. Janssen, J. van der Wijk, A. Fiedler, T. Schmidt, H. A.G.M. Sala, and S. U. Scheffler, "Remodelling of human hamstring autografts after anterior cruciate ligament reconstruction," Knee Surgery, Sports Traumatology, Arthroscopy, vol. 19, no. 8, pp. 1299-1306, 2011.

[4] R. A. Sachs, D. M. Daniel, M. L. Stone, and R. F. Garfein, "Patellofemoral problems after anterior cruciate ligament reconstruction," American Journal of Sports Medicine, vol. 17, no. 6, pp. 760-765, 1989.

[5] G. R. Barrett, F. K. Noojin, C. W. Hartzog, and C. R. Nash, "Reconstruction of the anterior cruciate ligament in females: a comparison of hamstring versus patellar tendon autograft," Arthroscopy, vol. 18, no. 1, pp. 46-54, 2002.

[6] B. D. Beynnon, R. J. Johnson, B. C. Fleming et al., "Anterior cruciate ligament replacement: comparison of bone-patellar tendon-bone grafts with two-strand hamstring grafts. A prospective, randomized study," Journal of Bone and Joint Surgery Series A, vol. 84, no. 9, pp. 1503-1513, 2002.

[7] D. W. Jackson, E. S. Grood, J. D. Goldstein et al., "A comparison of patellar tendon autograft and allograft used for anterior cruciate ligament reconstruction in the goat model," American Journal of Sports Medicine, vol. 21, no. 2, pp. 176185, 1993.
[8] G. Vunjak-Novakovic, G. Altman, R. Horan, and D. L. Kaplan, "Tissue engineering of ligaments," Annual Review of Biomedical Engineering, vol. 6, pp. 131-156, 2004.

[9] C. K. Kuo, J. E. Marturano, and R. S. Tuan, "Novel strategies in tendon and ligament tissue engineering: advanced biomaterials and regeneration motifs," Sports Medicine, Arthroscopy, Rehabilitation, Therapy and Technology, vol. 2, p. 20, 2010.

[10] R. B. Martin, D. B. Burr, and N. A. Sharkey, Skeletal Tissue Mechanics, Springer, New York, NY, USA, 1998.

[11] J. H. C. Wang, "Mechanobiology of tendon," Journal of Biomechanics, vol. 39, no. 9, pp. 1563-1582, 2006.

[12] M. Deie, T. Marui, C. R. Allen et al., "The effects of age on rabbit MCL fibroblast matrix synthesis in response to TGF$\beta 1$ or EGF," Mechanisms of Ageing and Development, vol. 97, no. 2, pp. 121-130, 1997.

[13] K. A. Hildebrand, S. L. Y. Woo, D. W. Smith et al., "The effects of platelet-derived growth factor-BB on healing of the rabbit medial collateral ligament. An in vivo study," American Journal of Sports Medicine, vol. 26, no. 4, pp. 549-554, 1998.

[14] P. G. Murphy, B. J. Loitz, C. B. Frank, and D. A. Hart, "Influence of exogenous growth factors on the synthesis and secretion of collagen types I and III by explants of normal and healing rabbit ligaments," Biochemistry and Cell Biology, vol. 72, no. 9-10, pp. 403-409, 1994.

[15] T. Marui, C. Niyibizi, H. I. Georgescu et al., "Effect of growth factors on matrix synthesis by ligament fibroblasts," Journal of Orthopaedic Research, vol. 15, no. 1, pp. 18-23, 1997.

[16] S. C. Scherping, C. C. Schmidt, H. I. Georgescu, C. K. Kwoh, C. H. Evans, and S. L. Y. Woo, "Effect of growth factors on the proliferation of ligament fibroblasts from skeletally mature rabbits," Connective Tissue Research, vol. 36, no. 1, pp. 1-8, 1997.

[17] M. L. Batten, J. C. Hansen, and L. E. Dahners, "Influence of dosage and timing of application of platelet-derived growth factor on early healing of the rat medial collateral ligament," Journal of Orthopaedic Research, vol. 14, no. 5, pp. 736-741, 1996.

[18] C. C. Schmidt, H. I. Georgescu, C. K. Kwoh et al., "Effect of growth factors on the proliferation of fibroblasts from the medial collateral and anterior cruciate ligaments," Journal of Orthopaedic Research, vol. 13, no. 2, pp. 184-190, 1995.

[19] E. A. DesRosiers, L. Yahia, and C. H. Rivard, "Proliferative and matrix synthesis response of canine anterior cruciate ligament fibroblasts submitted to combined growth factors," Journal of Orthopaedic Research, vol. 14, no. 2, pp. 200-208, 1996.

[20] A. K. Letson and L. E. Dahners, "The effect of combinations of growth factors on ligament healing," Clinical Orthopaedics and Related Research, no. 308, pp. 207-212, 1994.

[21] J. Lee, M. H. Green, and D. Amiel, "Synergistic effect of growth factors on cell outgrowth from explants of rabbit anterior cruciate and medial collateral ligaments," Journal of Orthopaedic Research, vol. 13, no. 3, pp. 435-441, 1995.

[22] D. Kobayashi, M. Kurosaka, S. Yoshiya, and K. Mizuno, "Effect of basic fibroblast growth factor on the healing of defects in the canine anterior cruciate ligament," Knee Surgery, Sports Traumatology, Arthroscopy, vol. 5, no. 3, pp. 189-194, 1997.

[23] K. Kobayashi, R. M. Healey, R. L. Sah et al., "Novel method for the quantitative assessment of cell migration: a study on the motility of rabbit anterior cruciate (ACL) and medial collateral ligament (MCL) cells," Tissue Engineering, vol. 6, no. 1, pp. 29-38, 2000.

[24] Y. Liu, A. Kalén, O. Risto, and O. Wahlström, "Fibroblast proliferation due to exposure to a platelet concentrate in vitro is 
pH dependent," Wound Repair and Regeneration, vol. 10, no. 5, pp. 336-340, 2002.

[25] M. M. Murray, K. P. Spindler, C. Devin et al., "Use of a collagen-platelet rich plasma scaffold to stimulate healing of a central defect in the canine ACL," Journal of Orthopaedic Research, vol. 24, no. 4, pp. 820-830, 2006.

[26] S. M. Joshi, A. N. Mastrangelo, E. M. Magarian, B. C. Fleming, and M. M. Murray, "Collagen-platelet composite enhances biomechanical and histologic healing of the porcine anterior cruciate ligament," American Journal of Sports Medicine, vol. 37, no. 12, pp. 2401-2410, 2009.

[27] F. Radice, R. Yánez, V. Gutiérrez, J. Rosales, M. Pinedo, and S. Coda, "Comparison of magnetic resonance imaging findings in anterior cruciate ligament grafts with and without autologous platelet-derived growth factors," Arthroscopy, vol. 26, no. 1 , pp. 50-57, 2010.

[28] M. M. Murray, K. P. Spindler, E. Abreu et al., "Collagenplatelet rich plasma hydrogel enhances primary repair of the porcine anterior cruciate ligament," Journal of Orthopaedic Research, vol. 25, no. 1, pp. 81-91, 2007.

[29] A. Silva and R. Sampaio, "Anatomic ACL reconstruction: does the platelet-rich plasma accelerate tendon healing?" Knee Surgery, Sports Traumatology, Arthroscopy, vol. 17, no. 6, pp. 676-682, 2009.

[30] J. R. Valentí Nin, G. Mora Gasque, A. Valentí Azcárate, J. D. Aquerreta Beola, and M. Hernandez Gonzalez, "Has plateletrich plasma any role in anterior cruciate ligament allograft healing?" Arthroscopy, vol. 25, no. 11, pp. 1206-1213, 2009.

[31] K. P. Spindler, M. M. Murray, J. L. Carey, D. Zurakowski, and B. C. Fleming, "The use of platelets to affect functional healing of an anterior cruciate ligament (ACL) autograft in a caprine ACL reconstruction model," Journal of Orthopaedic Research, vol. 27, no. 5, pp. 631-638, 2009.

[32] F. P. Barry, "Biology and clinical applications of mesenchymal stem cells," Birth Defects Research Part C, vol. 69, no. 3, pp. 250-256, 2003.

[33] A. I. Caplan, "Adult mesenchymal stem cells for tissue engineering versus regenerative medicine," Journal of Cellular Physiology, vol. 213, no. 2, pp. 341-347, 2007.

[34] A. I. Caplan, "Mesenchymal stem cells," Journal of Orthopaedic Research, vol. 9, no. 5, pp. 641-650, 1991.

[35] N. Watanabe, S. L. Y. Woo, C. Papageorgiou, C. Celechovsky, and S. Takai, "Fate of donor bone marrow cells in medial collateral ligament after simulated autologous transplantation," Microscopy Research and Technique, vol. 58, no. 1, pp. 39-44, 2002.

[36] W. Liu, B. Chen, D. Deng, F. Xu, L. Cui, and Y. Cao, "Repair of tendon defect with dermal fibroblast engineered tendon in a porcine model," Tissue Engineering, vol. 12, no. 4, pp. 775$788,2006$.

[37] E. Gentleman, G. A. Livesay, K. C. Dee, and E. A. Nauman, "Development of ligament-like structural organization and properties in cell-seeded collagen scaffolds in vitro," Annals of Biomedical Engineering, vol. 34, no. 5, pp. 726-736, 2006.

[38] T. G. Gerich, R. Kang, F. H. Fu, P. D. Robbins, and C. H. Evans, "Gene transfer to the rabbit patellar tendon: potential for genetic enhancement of tendon and ligament healing," Gene Therapy, vol. 3, no. 12, pp. 1089-1093, 1996.

[39] K. A. Hildebrand, M. Deie, C. R. Allen et al., "Early expression of marker genes in the rabbit medial collateral and anterior cruciate ligaments: the use of different viral vectors and the effects of injury," Journal of Orthopaedic Research, vol. 17, no. 1, pp. 37-42, 1999.
[40] A. F. Steinert, M. Weber, M. Kunz et al., "In situ IGF-1 gene delivery to cells emerging from the injured anterior cruciate ligament," Biomaterials, vol. 29, no. 7, pp. 904-916, 2008.

[41] N. Nakamura, K. Shino, T. Natsuume et al., "Early biological effect of in vivo gene transfer of platelet-derived growth factor (PDGF)-B into healing patellar ligament," Gene Therapy, vol. 5, no. 9, pp. 1165-1170, 1998.

[42] A. Pascher, A. F. Steinert, G. D. Palmer et al., "Enhanced repair of the anterior cruciate ligament by in situ gene transfer: evaluation in an in vitro model," Molecular Therapy, vol. 10, no. 2, pp. 327-336, 2004.

[43] J. Lou, Y. Tu, M. Burns, M. J. Silva, and P. Manske, "BMP12 gene transfer augmentation of lacerated tendon repair," Journal of Orthopaedic Research, vol. 19, no. 6, pp. 1199-1202, 2001.

[44] F. Goulet, L. Germain, D. Rancourt, C. Caron, A. Normand, and F. Auger, "Tendons and ligaments," in Principles of Tissue Engineering, R. Lanza, R. Langer, and W. Chick, Eds., pp. 633-643, RG Landes and Academic Press, Austin, Tex, USA, 1997.

[45] B. C. Fleming, E. M. Magarian, S. L. Harrison, D. J. Paller, and M. M. Murray, "Collagen scaffold supplementation does not improve the functional properties of the repaired anterior cruciate ligament," Journal of Orthopaedic Research, vol. 28, no. 6, pp. 703-709, 2010.

[46] D. Huang, T. R. Chang, A. Aggarwal, R. C. Lee, and H. P. Ehrlich, "Mechanisms and dynamics of mechanical strengthening in ligament- equivalent fibroblast-populated collagen matrices," Annals of Biomedical Engineering, vol. 21, no. 3, pp. 289-305, 1993.

[47] M. G. Dunn, J. B. Liesch, M. L. Tiku, and J. P. Zawadsky, "Development of fibroblast-seeded ligament analogs for ACL reconstruction," Journal of Biomedical Materials Research, vol. 29, no. 11, pp. 1363-1371, 1995.

[48] L. D. Bellincampi, R. F. Closkey, R. Prasad, J. P. Zawadsky, and M. G. Dunn, "Viability of fibroblast-seeded ligament analogs after autogenous implantation," Journal of Orthopaedic Research, vol. 16, no. 4, pp. 414-420, 1998.

[49] D. L. Butler, N. Juncosa-Melvin, G. P. Boivin et al., "Functional tissue engineering for tendon repair: a multidisciplinary strategy using mesenchymal stem cells, bioscaffolds, and mechanical stimulation," Journal of Orthopaedic Research, vol. 26, no. 1, pp. 1-9, 2008.

[50] K. R. C. Kinneberg, V. S. Nirmalanandhan, N. JuncosaMelvin et al., "Chondroitin-6-sulfate incorporation and mechanical stimulation increase MSC-collagen sponge construct stiffness," Journal of Orthopaedic Research, vol. 28, no. 8, pp. 1092-1099, 2010.

[51] H. Fan, H. Liu, S. L. Toh, and J. C. H. Goh, "Anterior cruciate ligament regeneration using mesenchymal stem cells and silk scaffold in large animal model," Biomaterials, vol. 30, no. 28, pp. 4967-4977, 2009.

[52] M. Santin, A. Motta, G. Freddi, and M. Cannas, "In vitro evaluation of the inflammatory potential of the silk fibroin," Journal of Biomedical Materials Research, vol. 46, no. 3, pp. 382-389, 1999.

[53] C. Wen, S. Ye, L. Zhou, and Y. Yu, "Silk-induced asthma in children: a report of 64 cases," Annals of Allergy, vol. 65, no. 5, pp. 375-378, 1990.

[54] S. Kurosaki, H. Otsuka, M. Kunitomo, M. Koyama, R. Pawankar, and K. Matumoto, "Fibroin allergy. IgE mediated hypersensitivity to silk suture materials," Nippon Ika Daigaku Zasshi, vol. 66, no. 1, pp. 41-44, 1999. 
[55] H. Yamada, H. Nakao, Y. Takasu, and K. Tsubouchi, "Preparation of undegraded native molecular fibroin solution from silkworm cocoons," Materials Science and Engineering C, vol. 14, no. 1, pp. 41-46, 2001.

[56] N. Minoura, M. Tsukada, and M. Nagura, "Physico-chemical properties of silk fibroin membrane as a biomaterial," Biomaterials, vol. 11, no. 6, pp. 430-434, 1990.

[57] G. H. Altman, R. L. Horan, H. H. Lu et al., "Silk matrix for tissue engineered anterior cruciate ligaments," Biomaterials, vol. 23, no. 20, pp. 4131-4141, 2002.

[58] H. Liu, H. Fan, Y. Wang, S. L. Toh, and J. C. H. Goh, "The interaction between a combined knitted silk scaffold and microporous silk sponge with human mesenchymal stem cells for ligament tissue engineering," Biomaterials, vol. 29, no. 6, pp. 662-674, 2008.

[59] X. Chen, Y. Y. Qi, L. L. Wang et al., "Ligament regeneration using a knitted silk scaffold combined with collagen matrix," Biomaterials, vol. 29, no. 27, pp. 3683-3692, 2008.

[60] S. L. Voytik-Harbin, A. O. Brightman, M. R. Kraine, B. Waisner, and S. F. Badylak, "Identification of extractable growth factors from small intestinal submucosa," Journal of Cellular Biochemistry, vol. 67, no. 4, pp. 478-491, 1997.

[61] C. A. McDevitt, G. M. Wildey, and R. M. Cutrone, "Transforming growth factor- $\beta 1$ in a sterilized tissue derived from the pig small intestine submucosa," Journal of Biomedical Materials Research Part A, vol. 67, no. 2, pp. 637-640, 2003.

[62] L. M. Dejardin, S. P. Arnoczky, and R. B. Clarke, "Use of small intestinal submucosal implants for regeneration of large fascial defects: an experimental study in dogs," Journal of Biomedical Materials Research, vol. 46, no. 2, pp. 203-211, 1999.

[63] S. F. Badylak, S. Arnoczky, P. Plouhar et al., "Naturally occurring extracellular matrix as a scaffold for musculoskeletal repair," Clinical Orthopaedics and Related Research, no. 367, pp. S333-S343, 1999.

[64] R. Liang, S. L. Y. Woo, Y. Takakura, D. K. Moon, F. Jia, and S. D. Abramowitch, "Long-term effects of porcine small intestine submucosa on the healing of medial collateral ligament: a functional tissue engineering study," Journal of Orthopaedic Research, vol. 24, no. 4, pp. 811-819, 2006.

[65] R. Liang, S. L. Y. Woo, T. D. Nguyen, P. C. Liu, and A. Almarza, "Effects of a bioscaffold on collagen fibrillogenesis in healing medial collateral ligament in rabbits," Journal of Orthopaedic Research, vol. 26, no. 8, pp. 1098-1104, 2008.

[66] V. Musahl, S. D. Abramowitch, T. W. Gilbert et al., "The use of porcine small intestinal submucosa to enhance the healing of the medial collateral ligament-a functional tissue engineering study in rabbits," Journal of Orthopaedic Research, vol. 22, no. 1, pp. 214-220, 2004.

[67] S. L. Y. Woo, Y. Takakura, R. Liang, F. Jia, and D. K. Moon, "Treatment with bioscaffold enhances the the fibril morphology and the collagen composition of healing medial collateral ligament in rabbits," Tissue Engineering, vol. 12, no. 1, pp. 159-166, 2006.

[68] M. E. Wiig, D. Amiel, J. VandeBerg, L. Kitabayashi, F. L. Harwood, and K. E. Arfors, "The early effect of high molecular weight hyaluronan (hyaluronic acid) on anterior cruciate ligament healing: an experimental study in rabbits," Journal of Orthopaedic Research, vol. 8, no. 3, pp. 425-434, 1990.

[69] T. Irie, T. Majima, N. Sawaguchi, T. Funakoshi, S.-I. Nishimura, and A. Minami, "Biomechanical and histologic evaluation of tissue engineered ligaments using chitosan and hyaluronan hybrid polymer fibers: a rabbit medial collateral ligament reconstruction model," Journal of Biomedical Materials Research Part A, vol. 97, no. 2, pp. 111-117, 2011.

[70] S. Rathbone, P. Furrer, J. Lübben, M. Zinn, and S. Cartmell, "Biocompatibility of polyhydroxyalkanoate as a potential material for ligament and tendon scaffold material," Journal of Biomedical Materials Research Part A, vol. 93, no. 4, pp. 1391-1403, 2010.

[71] G. A. Brody, M. Eisinger, S. P. Arnoczky, and R. F. Warren, "In vitro fibroblast seeding of prosthetic anterior cruciate ligaments. A preliminary study," American Journal of Sports Medicine, vol. 16, no. 3, pp. 203-208, 1988.

[72] M. G. Dunn, L. D. Bellincampi, A. J. Tria, and J. P. Zawadsky, "Preliminary development of a collagen-PLA composite for ACL reconstruction," Journal of Applied Polymer Science, vol. 63, no. 11, pp. 1423-1428, 1997.

[73] O. Laitinen, P. Tormala, R. Taurio et al., "Mechanical properties of biodegradable ligament augmentation device of poly(L-lactide) in vitro and in vivo," Biomaterials, vol. 13, no. 14, pp. 1012-1016, 1992.

[74] J. W. Freeman, M. D. Woods, and C. T. Laurencin, "Tissue engineering of the anterior cruciate ligament using a braidtwist scaffold design," Journal of Biomechanics, vol. 40, no. 9, pp. 2029-2036, 2007.

[75] H. H. Lu, J. A. Cooper, S. Manuel et al., "Anterior cruciate ligament regeneration using braided biodegradable scaffolds: in vitro optimization studies," Biomaterials, vol. 26, no. 23, pp. 4805-4816, 2005.

[76] H. W. Ouyang, J. C. H. Goh, X. M. Mo, S. H. Teoh, S. W. Chong, and E. H. Lee, "Study on cell-material systems for ACL regeneration: ligament cells and mesenchymal stem cells on various biodegradable polymeric films," Materials Science and Engineering C, vol. 20, p. 63, 2002.

[77] P. B. Van Wachem, T. Beugeling, and J. Feijen, "Interaction of cultured human endothelial cells with polymeric surfaces of different wettabilities," Biomaterials, vol. 6, no. 6, pp. 403408, 1985.

[78] F. R. Noyes and E. S. Grood, "The strength of the anterior cruciate ligament in humans and rhesus monkeys: age related and species related changes," Journal of Bone and Joint Surgery Series A, vol. 58, no. 8, pp. 1074-1082, 1976.

[79] E. Liljensten, K. Gisselfält, B. Edberg et al., "Studies of polyurethane urea bands for acl reconstruction," Journal of Materials Science, vol. 13, no. 4, pp. 351-359, 2002.

[80] K. Gisselfält, B. Edberg, and P. Flodin, "Synthesis and properties of degradable poly(urethane urea)s to be used for ligament reconstructions," Biomacromolecules, vol. 3, no. 5, pp. 951-958, 2002.

[81] M. Benjamin, E. J. Evans, and L. Copp, "The histology of tendon attachments to bone in man," Journal of Anatomy, vol. 149, pp. 89-100, 1986.

[82] R. R. Cooper and S. Misol, "Tendon and ligament insertion. A light and electron microscopic study," Journal of Bone and Joint Surgery Series A, vol. 52, no. 1, pp. 1-20, 1970.

[83] I. N. E. Wang, S. Mitroo, F. H. Chen, H. H. Lu, and S. B. Doty, "Age-dependent changes in matrix composition and organization at the ligament-to-bone insertion," Journal of Orthopaedic Research, vol. 24, no. 8, pp. 1745-1755, 2006.

[84] S. H. Liu, V. Panossian, R. Al-Shaikh et al., "Morphology and matrix composition during early tendon to bone healing," Clinical Orthopaedics and Related Research, no. 339, pp. 253260, 1997.

[85] S. A. Rodeo, S. P. Arnoczky, P. A. Torzilli, C. Hidaka, and R. F. Warren, "Tendon-healing in a bone tunnel. A biomechanical 
and histological study in the dog," Journal of Bone and Joint Surgery Series A, vol. 75, no. 12, pp. 1795-1803, 1993.

[86] H. H. Lu, S. D. Subramony, M. K. Boushell, and X. Zhang, "Tissue engineering strategies for the regeneration of orthopedic interfaces," Annals of Biomedical Engineering, vol. 38, no. 6, pp. 2142-2154, 2010.

[87] H. Mutsuzaki, M. Sakane, H. Nakajima et al., "Calciumphosphate-hybridized tendon directly promotes regeneration of tendon-bone insertion," Journal of Biomedical Materials Research Part A, vol. 70, no. 2, pp. 319-327, 2004.

[88] S. Yamazaki, K. Yasuda, F. Tomita, H. Tohyama, and A. Minami, "The effect of transforming growth factor- $\beta 1$ on intraosseous healing of flexor tendon autograft replacement of anterior cruciate ligament in dogs," Arthroscopy, vol. 21, no. 9, pp. 1034-1041, 2005.

[89] S. A. Rodeo, K. Suzuki, X. H. Deng, J. Wozney, and R. F. Warren, "Use of recombinant human bone morphogenetic protein-2 to enhance tendon healing in a bone tunnel," American Journal of Sports Medicine, vol. 27, no. 4, pp. 476-488, 1999.

[90] C. H. Chen, H. W. Liu, C. L. Tsai, C. M. Yu, I. H. Lin, and G. H. Hsiue, "Photoencapsulation of bone morphogenetic protein-2 and periosteal progenitor cells improve tendon graft healing in a bone tunnel," American Journal of Sports Medicine, vol. 36, no. 3, pp. 461-473, 2008.

[91] V. Martinek, C. Latterman, A. Usas et al., "Enhancement of tendon-bone integration of anterior cruciate ligament grafts with bone morphogenetic protein-2 gene transfer: a histological and biomechanical study," Journal of Bone and Joint Surgery Series A, vol. 84, no. 7, pp. 1123-1131, 2002.

[92] G. H. Altman, R. L. Horan, P. Weitzel, and J. C. Richmond, "The use of long-term bioresorbable scaffolds for anterior cruciate ligament repair," Journal of the American Academy of Orthopaedic Surgeons, vol. 16, no. 4, pp. 177-187, 2008.

[93] J. A. Cooper, H. H. Lu, F. K. Ko, J. W. Freeman, and C. T. Laurencin, "Fiber-based tissue-engineered scaffold for ligament replacement: design considerations and in vitro evaluation," Biomaterials, vol. 26, no. 13, pp. 1523-1532, 2005.

[94] J. Z. Paxton, K. Donnelly, R. P. Keatch, and K. Baar, "Engineering the bone-ligament interface using polyethylene glycol diacrylate incorporated with hydroxyapatite," Tissue Engineering Part A, vol. 15, no. 6, pp. 1201-1209, 2009.

[95] J. P. Spalazzi, E. Dagher, S. B. Doty, X. E. Guo, S. A. Rodeo, and H. H. Lu, "In vivo evaluation of a multiphased scaffold designed for orthopaedic interface tissue engineering and soft tissue-to-bone integration," Journal of Biomedical Materials Research Part A, vol. 86, no. 1, pp. 1-12, 2008.

[96] J. P. Spalazzi, S. B. Doty, K. L. Moffat, W. N. Levine, and H. $\mathrm{H}$. Lu, "Development of controlled matrix heterogeneity on a triphasic scaffold for orthopedic interface tissue engineering," Tissue Engineering, vol. 12, no. 12, pp. 3497-3508, 2006.

[97] J. Z. Paxton, L. M. Grover, and K. Baar, "Engineering an in vitro model of a functional ligament from bone to bone," Tissue Engineering Part A, vol. 16, no. 11, pp. 3515-3525, 2010.

[98] J. Ma, M. J. Smietana, T. Y. Kostrominova, E. M. Wojtys, L. M. Larkin, and E. M. Arruda, "Three-dimensional engineered bone-ligament-bone constructs for anterior cruciate ligament replacement," Tissue Engineering Part A. In press.

[99] R. A. Orlando and D. A. Cheresh, "Arginine-glycine-aspartic acid binding leading to molecular stabilization between integrin $\alpha(\mathrm{v}) \beta 3$ and its ligand," Journal of Biological Chemistry, vol. 266, no. 29, pp. 19543-19550, 1991.
[100] S. J. Kew, J. H. Gwynne, D. Enea et al., "Regeneration and repair of tendon and ligament tissue using collagen fibre biomaterials," Acta Biomaterialia, vol. 7, no. 9, pp. 3237-3247, 2011.

[101] M. Garcia-Fuentes, A. J. Meinel, M. Hilbe, L. Meinel, and H. P. Merkle, "Silk fibroin/hyaluronan scaffolds for human mesenchymal stem cell culture in tissue engineering," Biomaterials, vol. 30, no. 28, pp. 5068-5076, 2009.

[102] J. Zhou, M. Ciobanu, G. Pavon-Djavid, V. Gueguen, and V. Migonney, "Morphology and adhesion of human fibroblast cells cultured on bioactive polymer grafted ligament prosthesis," Conference Proceedings of IEEE Engineering in Medicine and Biology Society, vol. 2007, pp. 5115-5118, 2007.

[103] J. C. H. Goh, H. W. Ouyang, S. H. Teoh, C. K. C. Chan, and E. H. Lee, "Tissue-engineering approach to the repair and regeneration of tendons and ligaments," Tissue Engineering, vol. 9, no. 1, pp. S31-S44, 2003.

[104] J. Garvin, J. Qi, M. Maloney, and A. J. Banes, "Novel system for engineering bioartificial tendons and application of mechanical load," Tissue Engineering, vol. 9, no. 5, pp. 967979, 2003.

[105] G. H. Altman and R. L. Horan, "Tissue engineering of ligaments," in An Introduction of Biomaterials, S. A. Guelcher and J. O. Hollinger, Eds., pp. 499-524, CRC Pres, Boca Raton, Fla, USA, 2006.

[106] R. I. Abousleiman and V. I. Sikavitsas, "Bioreactors for tissues of the musculoskeletal system," Advances in Experimental Medicine and Biology, vol. 585, pp. 243-259, 2006.

[107] G. H. Altman, H. H. Lu, R. L. Horan et al., "Advanced bioreactor with controlled application of multi-dimensional strain for tissue engineering," Journal of Biomechanical Engineering, vol. 124, no. 6, pp. 742-749, 2002.

[108] G. H. Altman, R. L. Horan, I. Martin et al., "Cell differentiation by mechanical stress," The FASEB Journal, vol. 16, no. 2, pp. 270-272, 2002.

[109] H. A. Benhardt and E. M. Cosgriff-Hernandez, "The role of mechanical loading in ligament tissue engineering," Tissue Engineering Part B, vol. 15, no. 4, pp. 467-475, 2009.

[110] S. A. Park, I. A. Kim, Y. J. Lee et al., "Biological responses of ligament fibroblasts and gene expression profiling on micropatterned silicone substrates subjected to mechanical stimuli," Journal of Bioscience and Bioengineering, vol. 102, no. 5, pp. 402-412, 2006.

[111] C. H. Lee, H. J. Shin, I. H. Cho et al., "Nanofiber alignment and direction of mechanical strain affect the ECM production of human ACL fibroblast," Biomaterials, vol. 26, no. 11, pp. 1261-1270, 2005.

[112] U. Nöth, K. Schupp, A. Heymer et al., "Anterior cruciate ligament constructs fabricated from human mesenchymal stem cells in a collagen type I hydrogel," Cytotherapy, vol. 7, no. 5, pp. 447-455, 2005.

[113] J. Chen, R. L. Horan, D. Bramono et al., "Monitoring mesenchymal stromal cell developmental stage to apply on-time mechanical stimulation for ligament tissue engineering," Tissue Engineering, vol. 12, no. 11, pp. 3085-3095, 2006.

[114] I. C. Lee, J. H. Wang, Y. T. Lee, and T. H. Young, "The differentiation of mesenchymal stem cells by mechanical stress or/and co-culture system," Biochemical and Biophysical Research Communications, vol. 352, no. 1, pp. 147-152, 2007.

[115] N. Juncosa-Melvin, K. S. Matlin, R. W. Holdcraft, V. S. Nirmalanandhan, and D. L. Butler, "Mechanical stimulation increases collagen type I and collagen type III gene expression of stem cell-collagen sponge constructs for patellar tendon 
repair, Tissue Engineering, vol. 13, no. 6, pp. 1219-1226, 2007.

[116] G. Yang, R. C. Crawford, and J. H. C. Wang, "Proliferation and collagen production of human patellar tendon fibroblasts in response to cyclic uniaxial stretching in serum-free conditions," Journal of Biomechanics, vol. 37, no. 10, pp. 1543-1550, 2004.

[117] T. Toyoda, H. Matsumoto, K. Fujikawa, S. Saito, and K. Inoue, "Tensile load and the metabolism of anterior cruciate ligament cells," Clinical Orthopaedics and Related Research, no. 353, pp. 247-255, 1998.

[118] B. S. Kim, J. Nikolovski, J. Bonadio, and D. J. Mooney, “Cyclic mechanical strain regulates the development of engineered smooth muscle tissue," Nature Biotechnology, vol. 17, no. 10, pp. 979-983, 1999.

[119] D. R. Henshaw, E. Attia, M. Bhargava, and J. A. Hannafin, "Canine ACL fibroblast integrin expression and cell alignment in response to cyclic tensile strain in three-dimensional collagen gels," Journal of Orthopaedic Research, vol. 24, no. 3, pp. 481-490, 2006.

[120] J. A. Hannafin, E. A. Attia, R. Henshaw, R. F. Warren, and M. M. Bhargava, "Effect of cyclic strain and plating matrix on cell proliferation and integrin expression by ligament fibroblasts," Journal of Orthopaedic Research, vol. 24, no. 2, pp. 149-158, 2006.

[121] S. P. Arnoczky, T. Tian, M. Lavagnino, K. Gardner, P. Schuler, and P. Morse, "Activation of stress-activated protein kinases (SAPK) in tendon cells following cyclic strain: the effects of strain frequency, strain magnitude, and cytosolic calcium," Journal of Orthopaedic Research, vol. 20, no. 5, pp. 947-952, 2002.

[122] M. Skutek, M. Van Griensven, J. Zeichen, N. Brauer, and U. Bosch, "Cyclic mechanical stretching modulates secretion pattern of growth factors in human tendon fibroblasts," European Journal of Applied Physiology, vol. 86, no. 1, pp. 48-52, 2001.

[123] D. Zhou, H. S. Lee, F. Villarreal et al., "Differential MMP-2 activity of ligament cells under mechanical stretch injury: an in vitro study on human ACL and MCL fibroblasts," Journal of Orthopaedic Research, vol. 23, no. 4, pp. 949-957, 2005. 

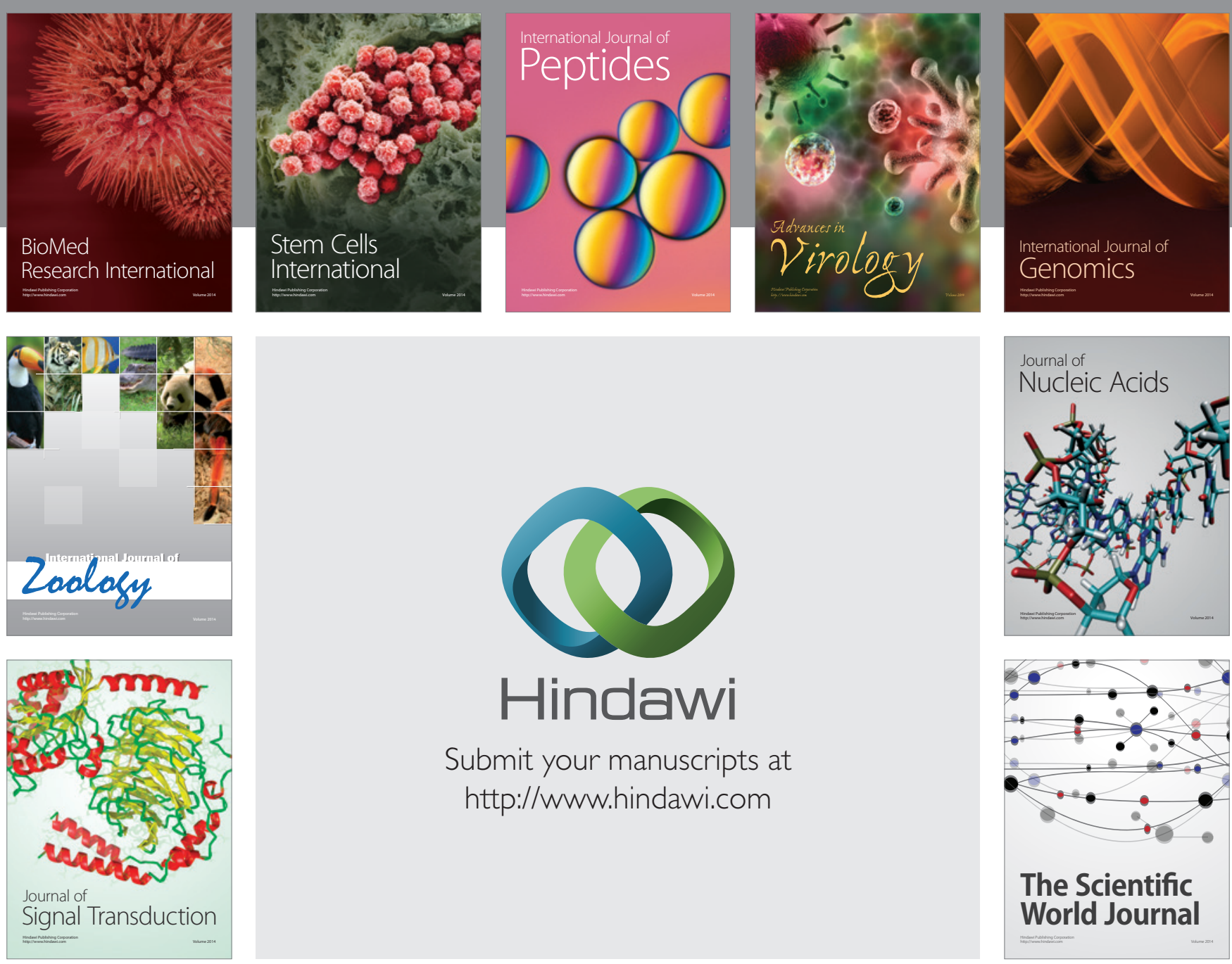

Submit your manuscripts at

http://www.hindawi.com
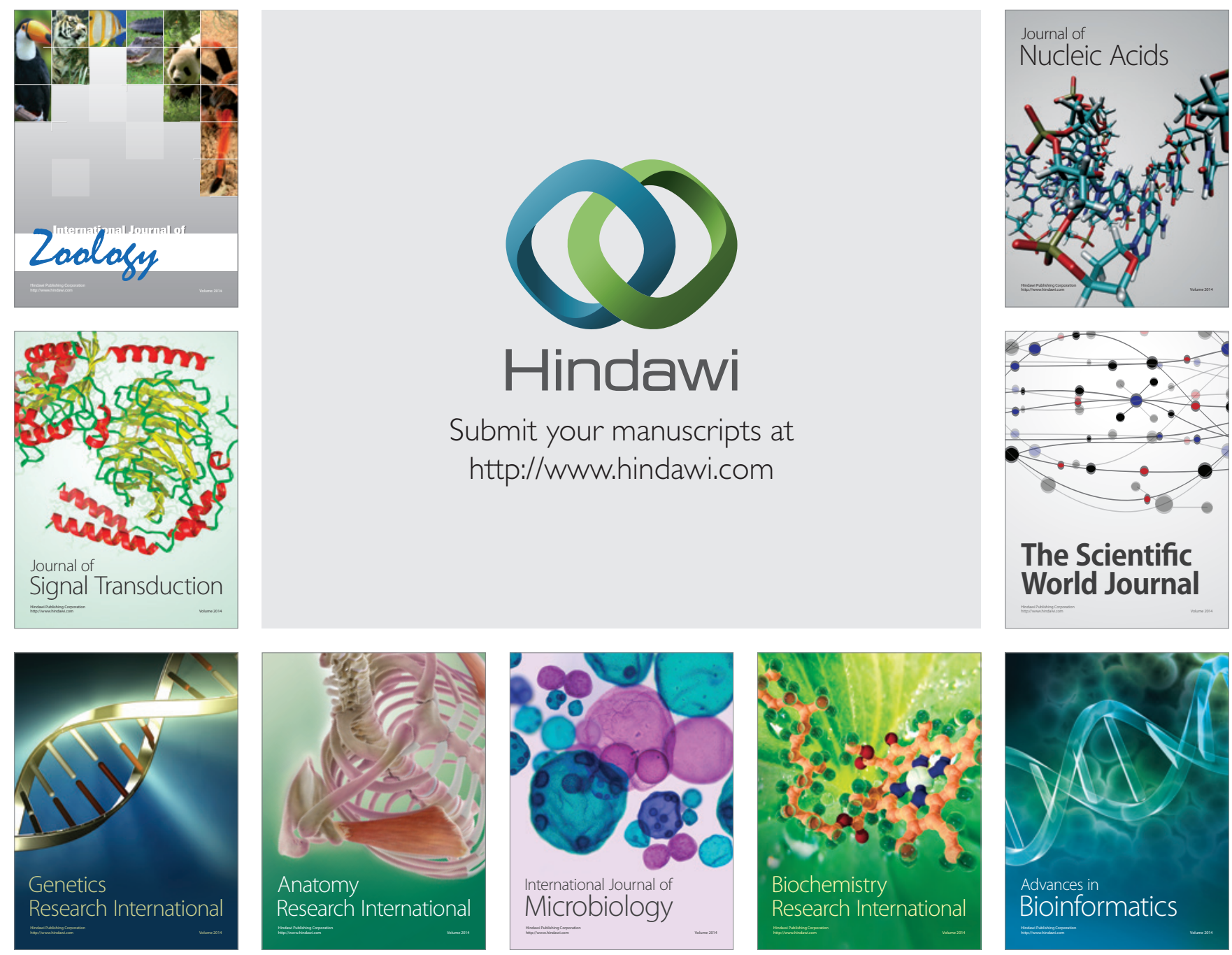

The Scientific World Journal
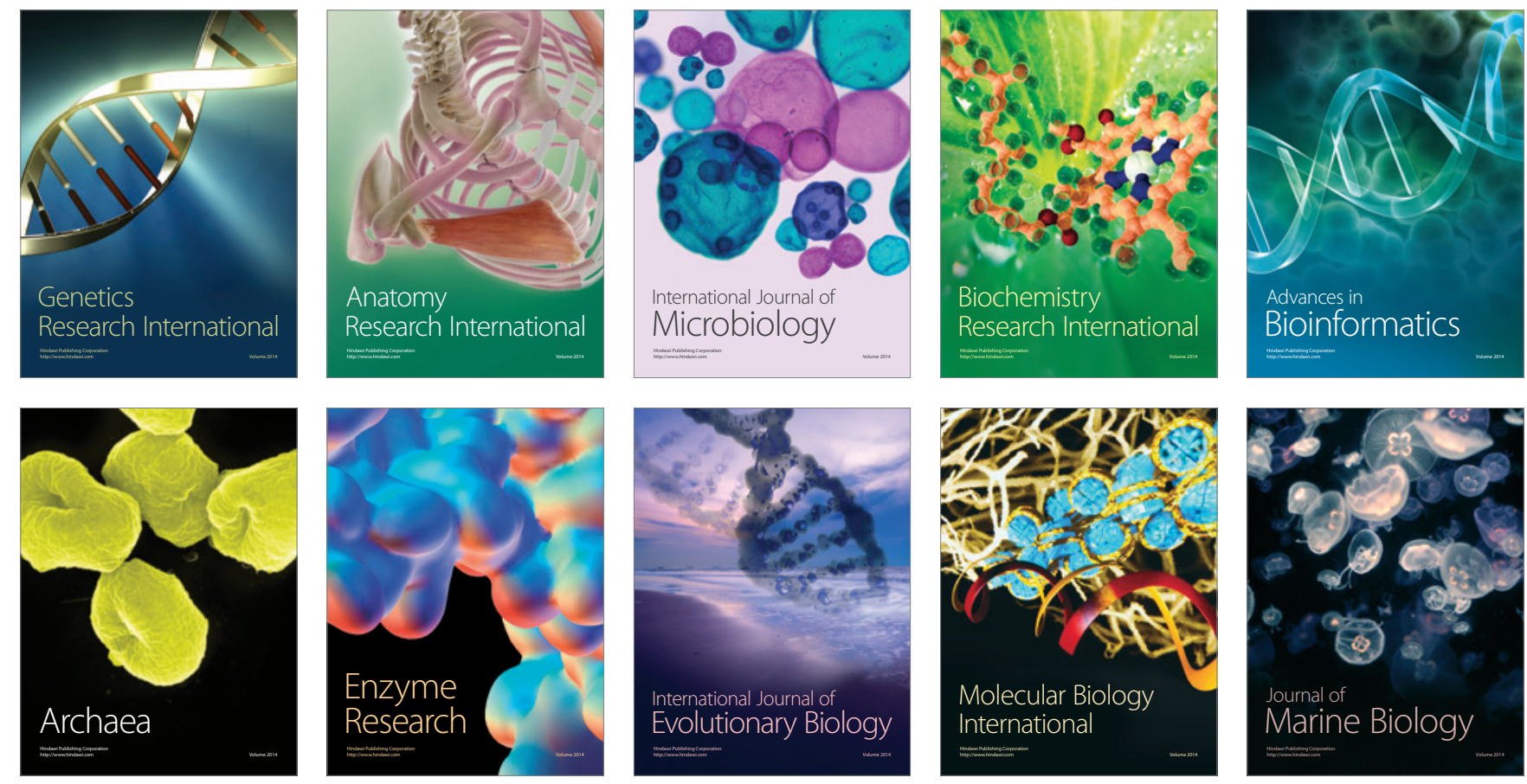